\title{
Elementos estruturantes para a realização da coprodução do bem público: uma visão integrativa
}

\author{
ARlindo Carvalho Rocha ${ }^{1}$ \\ PAULA CHIES SCHOMMER ${ }^{1}$ \\ EMILIANA DEBETIR ${ }^{1}$ \\ DANiEl MORAes Pinheiro ${ }^{1}$
}

${ }^{1}$ UnIVERSIDAde do ESTAdo de SANTA CATARINA (UDESC) / CENTRO DE CIÊNCIAS DA ADMINISTRAÇÃo E SOCIOECONÔMICAS (ESAG), FLORIANÓPOLIS - SC, BRASIL

\begin{abstract}
Resumo
Neste artigo discute-se a realização da coprodução de bens e serviços público a partir de uma visão integrativa. Parte-se da proposição de que transparência, informação, confiança, participação e accountability são elementos estruturantes da coprodução. Sugere-se, a partir daí, uma visão integrativa desse fenômeno com base na abordagem de Mary Parker Follett, considerando as inter-relações desses elementos para fundamentar a necessária compreensão de um processo complexo, multifacetado e deliberado. Trata-se de um estudo teórico-analítico, combinando elementos indutivos e dedutivos, com abordagem qualitativa, por meio de revisão narrativa e revisão sistemática da produção acadêmica nacional e internacional. Como resultado, destaca-se que a coprodução de bens e serviços públicos é uma tarefa complexa assentada na perspectiva sistêmica da associação de indivíduos em grupo. Aponta-se, ainda, a presença de elementos inter-relacionados e demanda por coesão social, a qual pode ser tanto consequência como catalisadora desses elementos nos processos de coprodução.
\end{abstract}

Palavras-chave: Coprodução. Visão integrativa. Elementos estruturantes.

\section{Structural elements for the co-production of public goods: an integrative approach}

\section{Abstract}

This article discusses the co-production of public goods and services from an integrative view. It starts from the proposition that transparency, information, trust, participation, and accountability are structural elements of co-production to suggest an integrative view of this phenomenon based on the approach of Mary Parker Follett, considering the interrelationships of these elements to support the necessary understanding of a complex, multifaceted, and deliberate process. This is a theoretical-analytical study, combining inductive and deductive elements, with a qualitative approach, through narrative review and systematic review of the national and international academic production. The results emphasize that the co-production of public goods and services is a complex task based on the systemic perspective of the association of individuals in groups, pointing to the presence of interrelated elements, and demanding social cohesion that can be consequential and catalyst of these elements.

Keywords: Co-production. Integrative view. Structuring elements.

\section{Elementos estructurantes para la realización de la coproducción del bien público: una visión integradora}

\section{Resumen}

Este artículo analiza la realización de la coproducción de bienes y servicios públicos desde una visión integradora. Se parte de la proposición de que la transparencia, la información, la confianza, la participación y la rendición de cuentas son elementos estructurantes de la coproducción para sugerir una visión integradora de este fenómeno a partir del enfoque de Mary Parker Follett, considerando las interrelaciones de estos elementos para fundamentar la comprensión necesaria de un proceso complejo, multifacético y deliberado. Sin embargo, no se avanza en proponer un modelo de análisis. Es un estudio teórico-analítico, que combina elementos inductivos y deductivos, con un enfoque cualitativo, mediante revisión narrativa y revisión sistemática de la producción académica nacional e internacional. Como resultado, se destaca que la coproducción de bienes y servicios públicos es una tarea compleja que se fundamenta en la perspectiva sistémica de la asociación de individuos en grupo y que señala la presencia de elementos interrelacionados y demanda cohesión social, que puede ser tanto consecuencia como catalizadora de estos elementos.

Palabras clave: Coproducción. Visión integradora. Elementos estructurantes. 


\section{INTRODUÇÃO}

A coprodução do bem público pode ser definida como o engajamento mútuo entre governantes e cidadãos, que mobilizam recursos disponíveis na sociedade e compartilham responsabilidades e poder, para produzir bens e serviços públicos (Brudney \& England, 1983; Denhardt \& Denhardt, 2007; Marschall, 2004; Roberts, 2004; Salm \& Menegasso, 2010; Verschuere, Brandsen \& Pestoff, 2012).

O interesse pela coprodução cresceu a partir da crise financeira global iniciada em 2008, pois esta aumentou a necessidade de austeridade e cortes no setor público, em diversos países (Bovaird, Flemig, Loeffler \& Osborne, 2017). Tal interesse se explica, uma vez que, como afirmam Brandsen e Honingh (2016, p. 431), a coprodução de bens e serviços públicos pode constituir-se em um meio de acesso a recursos da sociedade que, de outra forma, não estariam à disposição dos governos e, portanto, servir como resposta à escassez de recursos e de legitimidade governamentais. Ademais, agiria "como parte de um impulso mais geral para revigorar a participação voluntária e reforçar a coesão social, numa sociedade cada vez mais fragmentada e individualizada".

Todavia, a coprodução é uma tarefa complexa. Estudos que exploram e analisam processos de coprodução em experiências empíricas nacionais e internacionais apontam que esses processos demandam e dependem da integração de elementos como transparência, informação, confiança, participação e accountability, que possibilitam o engajamento mútuo de usuários e provedores regulares (ou cidadãos e governantes) para a sua realização (Alford, 2009; Bovaird, 2007; Bovaird \& Loefler, 2013; Brandsen \& Honingh, 2016; Denhardt \& Denhardt, 2007; Doin, Dahmer, Schommer \& Spaniol, 2012; Guerzovich \& Schommer, 2016; Pestoff, 2009, 2018a; Rocha, Schommer, Debetir \& Pinheiro, 2019; Rocha, Schommer, Spaniol \& Sousa, 2012; Scharff, 2011; Schommer, Rocha, Spaniol, Dahmer \& Sousa, 2015).

Tais elementos são apresentados ora como condições necessárias - ponto de partida -, ora como decorrências da coprodução, que podem ser reforçados, transformados, ampliados ou destruídos no decorrer do processo. Há, entretanto, uma lacuna na compreensão dos papéis que esses elementos desempenham nesse contexto e quais as inter-relações entre eles, ainda que se possa inferir que a coprodução demanda e depende da sua integração para se desenvolver.

A origem do presente trabalho está, portanto, nesse conjunto de estudos que evidenciam conexões entre esses elementos, mormente aqueles que exploram a interface entre coprodução e accountability (Doin et al., 2012; Guerzovich \& Schommer, 2016; Rocha et al., 2012; Rocha et al., 2019; Schommer et al., 2015).

Em termos metodológicos, buscou-se, mediante pesquisa de caráter teórico-analítico, combinar elementos indutivos e dedutivos na construção das inter-relações entre os elementos. A partir de uma revisão bibliográfica narrativa (Rother, 2007) da produção acadêmica nacional e internacional, na qual são selecionados os autores principais dos temas com base no conhecimento dos pesquisadores (Paré, Trudel, Jaana \& Kitsiou, 2015) e, principalmente, nos estudos referenciados, considerou-se, em um primeiro momento, a existência das inter-relações entre os elementos da coprodução. Na sequência efetuou-se a revisão sistemática (Rother, 2007) de cada um desses conceitos e a identificação das conexões entre eles. A seguir, adotando a visão integrativa defendida por Mary Parker Follett, tal como reunida e analisada na obra de Stout e Love (2017), fundamentaram-se as bases necessárias à compreensão dessas inter-relações e dos caminhos para o desenvolvimento de um modelo de análise da coprodução fundada na coesão social, aqui entendida em sentido sociológico mais comum, relativo à integração dos indivíduos em um grupo social com base em algum tipo de motivação.

Discutem-se, portanto, elementos que se propõe serem estruturantes da coprodução de serviços públicos, buscando estudá-los e compreendê-los de forma ampla no bojo de processos complexos como os da coprodução, a partir dos pressupostos ontológicos e os elementos integrativos que consagram a perspectiva sistêmica da associação e atuação dos seres humanos em grupo (Follett, 1998 [1918]; Stout \& Love, 2017).

Nesse sentido, a sinergia potencialmente gerada pela coprodução, conforme analisada por Ostrom (1996), já era mencionada no trabalho de Follett ao ressaltar a cocriarão como processo decorrente da criatividade humana e a necessidade que o ser humano tem, para se realizar, de cocriar e participar ativamente da vida na comunidade.

A governança follettiana, portanto, está alinhada com as atuais perspectivas de governança colaborativa (Emerson, Nabatchi \& Balogh, 2012), governança democrática em rede (Denhardt, 2012), cocrição e coprodução (Brandsen, Steen \& Verschuere, 2018). Entretanto, para além de uma perspectiva instrumental que eventualmente assumem os estudos relativos a esses temas, 
o traço particular da contribuição de Follett é sua ênfase na integração e na ontologia do processo relacional que fundamenta o seu trabalho, baseado em conhecimentos de diversos campos da ciência. Segundo Follett, para que a humanidade possa agir (co-agir) e interagir de modo mais coeso e harmonioso, transformando aspectos da ética, da política e da economia, é essencial reconhecer e refletir sobre os princípios que baseiam qualquer atividade humana (Stout \& Love, 2017).

A perspectiva integrativa, uma vez compreendida e praticada, constitui a resposta (ou a aposta) de Follett, inclusive em contextos de conflito. Portanto, ainda que as características do contexto não favoreçam a ação conjunta entre cidadãos e governantes, a confiança, a colaboração e o conhecimento compartilhado seriam caminhos que se apresentariam como contrapontos possíveis (ou necessários) para evitar o colapso social e o desperdício das capacidades humanas, justificando e enfatizando a discussão sobre as inter-relações entre esses elementos e a sua integração nesses processos.

Tal perspectiva se coaduna à visão da coesão social como o amálgama da coprodução que orienta este estudo. Mais do que outras perspectivas de governança, a follettiana facilita a análise dos elementos constitutivos dos processos sociais envolvidos em cada um dos elementos estruturantes aqui focalizados. Essa discussão pode contribuir não só para aprimorar futuros modelos de análise do fenômeno da coprodução como, também, indicar estratégias de enfrentamento dos problemas práticos decorrentes de sua implantação, incluindo a atuação de gestores públicos na facilitação de modos de associações por meio de processos relacionais.

Em resumo, este estudo propõe discutir, utilizando-se de uma visão integrativa para fundamentar a necessária compreensão de um processo complexo, multifacetado e deliberado, os elementos transparência, informação, confiança, participação e accountability como estruturantes da coprodução e amálgama da coesão social e vislumbrar caminhos para o desenvolvimento de um modelo de análise. Todavia, este trabalho não pretende avançar na proposição do modelo propriamente dito. Para que isso seja possível, faz-se necessário um exame detalhado com base em pesquisas empíricas estruturadas de cada elemento constitutivo e suas inter-relações com os demais, de forma a responder questões objetivas necessárias à sua construção, o que não é o caso aqui.

Para cumprir a discussão proposta, o artigo está organizado em cinco tópicos, a contar desta introdução. No segundo tópico faz-se uma breve explanação sobre o processo integrativo, com base na teoria administrativa de Mary Parker Follett. As inter-relações dos elementos presentes na coprodução são discutidas e analisadas ao longo do terceiro tópico. No quarto tópico são apresentadas as considerações finais e, a seguir, as referências.

\section{O PROCESSO INTEGRATIVO}

A coprodução é um fenômeno complexo cuja compreensão remete às bases da teoria administrativa de Mary Parker Follett, e sua concepção de gerenciamento de organizações e sistemas sociais, que tem no processo integrativo sua essência. A obra de Follett respondia às condições sociais de seu tempo, em muitos aspectos similares às atuais. E esse vínculo se torna ainda mais pertinente ao se considerar que, hoje em dia, tais condições são ainda mais evidentes e os desafios quiçá mais urgentes.

Ao refletir sobre o contexto histórico em que trabalhava (última década do século XIX até 1933, ano da sua morte), Follett afirmava que as maiores necessidades da sociedade eram decorrentes da exploração crescente de recursos naturais; de uma competição acentuada e, por vezes, predadora; da carência de trabalho em vista da crescente oferta de mão de obra; do desenvolvimento de uma concepção mais ampla da ética das relações humanas; da expansão de uma visão das empresas como um serviço público, que amplia as suas responsabilidades por condutas eficientes. Não sem motivo, portanto, Stout e Love (2017) afirmam a atualidade e o interesse de diversas áreas da administração pelo trabalho de Follett, e destacam:

Se relermos Follett com um entendimento de uma ONTOLOGIA DO PROCESSO RELACIONAL QUE ABRAÇA A DIFERENÇA E BUSCA A HARMONIA, então as recomendações da autora para a prática política e administrativa são não apenas bastante lógicas, mas necessárias. [...] Não precisamos impor o relacionamento pela ordem, pois ele é uma certeza ontológica. Contudo, PODEMOS FOMENTÁ-LO OU REPRIMI-LO POR MEIO DE NOSSAS PRÁTICAS E ESTRUTURAS INSTITUCIONAIS. [...] Essa é a noção básica daquilo que pode ser chamado de governança follettiana: a facilitação de um modo de associação por meio de um processo relacional do vir a ser de indivíduos únicos, coletivamente engajados em um processo contínuo de harmonizar diferenças através de redes interligadas, para progredir como indivíduos e como sociedade [destaques no original] (Stout \& Love, 2017, pp. 356-357). 
O pensamento de Follett, ainda que aqui reproduzido de forma restrita, permite antever a importância da sua obra para a compreensão dos fundamentos da coprodução, pois para a autora, o processo integrativo é, em síntese "a lei básica da vida [...] suporta a estrutura de toda vida e orienta toda atividade" (Stout \& Love, 2017, p. 359).

Aplicando-se a perspectiva do processo integrativo à coprodução, tem-se a ideia de um processo contínuo, interativo e criativo, e não apenas de produto que se busque atingir, pois "A integração é o conceito fundamental de Follett, o qual ela aplica igualmente à existência física, à psique individual e a grupos de seres humanos em todos os contextos sociais" (Stout \& Love, 2017, p. 359). E, como já frisado, mesmo observando-se o cenário atual de acirramento do extremismo e da competição que têm contribuindo para o crescimento das tensões sociais e para o questionamento das instituições de governança nacional e global, ou seja, o acirramento do conflito, a resposta de Follett é pertinente, pois o conflito não é ignorado, mas visto como etapa de um processo integrativo, criativo e colaborativo, por meio do qual se buscam alternativas e soluções para desafios coletivos (Stout \& Love, 2017).

Nesse sentido, os elementos que compõem e estruturam a coprodução são não apenas inter-relacionados, mas dinâmica e mutuamente influentes.

Com isso, o processo demanda e induz o gestor público a um papel proativo na busca pela coprodução: coordenar um processo integrativo de elementos, funções e interesses convergentes.

\section{ELEMENTOS ESTRUTURANTES: INTER-RELAÇÕES}

Feita esta breve contextualização teórica, passa-se à discussão de cada um dos elementos estruturantes da coprodução do bem público.

\section{Transparência}

A demanda da sociedade por transparência pública, entendida como o fluxo aberto de informações criado pelo governo e orientado aos cidadãos, tem crescido em diversos países e está determinada em leis em mais de 100 deles (Angélico, 2015). Segundo Park e Blenkinsopp (2011, p. 256), essa demanda tem origem em três fatores principais: "Primeiro, a transparência é uma das reivindicações morais fundamentais nas sociedades democráticas [...]. Em segundo lugar, a transparência é uma das medidas práticas tomadas para reduzir a corrupção [...]. Em terceiro lugar, a transparência tem um efeito positivo na confiança e na accountability.

Em uma conjuntura na qual sobressaia a opacidade, a desinformação e a falta de confiança recíproca entre cidadão e governo e destes em relação ao sistema político, promover a coprodução é, no mínimo, desafiador. Em contextos desfavoráveis como esse, a transparência, como proposta de governo, pode ser uma estratégia para superar esse problema. É o caso de um programa analisado por Rocha et al. (2019, p. 19), que promove a participação cidadã em diferentes etapas da provisão do serviço de pavimentação de vias, tendo a transparência como característica-chave da gestão governamental local. Afirmam os autores que "A transparência no processo favoreceu a confiança e o engajamento mútuo entre governantes e cidadãos, equilibrando suas expectativas diante da realidade municipal e promovendo conhecimento sobre a produção do serviço público".

Ou seja, considerado o seu potencial para estabelecer bases de confiança, a transparência como uma estratégica de governo pode ser um efetivo impulsionador para a realização de ações de forma compartilhada, promovendo a accountability e contribuindo para a melhoria na prestação de serviços públicos (Bovaird \& Loefler, 2013), além de revigorar a legitimidade e a confiança no governo e no sistema político (Brandsen \& Honingh, 2016).

Entretanto, existem riscos a serem enfrentados. Podem ou tendem a surgir (ainda que disfarçadas) pressões dos grupos que não têm interesse na transparência dos atos do governo; além do risco de o próprio governo ser contestado, se houver denúncias ou razões para se acreditar que a transparência não correspondeu ao que se divulgou. Até mesmo o distanciamento entre cidadãos e governantes; as poucas oportunidades de participação; a transparência "seletiva", quanto a itens sensíveis como recursos, critérios e procedimentos etc.; a percepção de que há um distanciamento em relação ao processo de tomada de decisões ou; ainda, se não houver capacidade de enforcement da própria estratégia, podem comprometer o processo, levando-o ao descrédito generalizado. 
De qualquer forma, a transparência, ainda que necessária, por si só não é suficiente. Sua contribuição ao processo é proporcionar a divulgação de informações, que são fundamentos para o conhecimento, além de propiciar bases para processos de comunicação, construção de consensos e diálogo sobre valores compartilhados, que podem levar à ampliação da confiança recíproca.

\section{Informação para o conhecimento}

A informação é algo imaterial e nesse aspecto relaciona-se - 'essencialmente' - com o conhecimento, dado que a informação, "quando percebida, confrontada aos conhecimentos existentes, e aceita (consciente ou inconscientemente), incorpora-se ao conhecimento existente, o qual, quando estruturado, torna-se saber" (Robredo, 2011, p. 18).

A obtenção e absorção de informações e, consequentemente, do conhecimento, dependem da vontade individual e decorrem do interesse da sociedade. São elementos ativos no desenvolvimento da coprodução, dado que permitem ao cidadão construir um quadro referencial sobre os problemas públicos e a ação do governo e, a partir dele, atuar no sentido de contribuir para as soluções, e exigir que os representantes expliquem as suas ações, mudem sua forma de agir ou mesmo alterem os objetivos das políticas públicas. "Publicizar o que se faz, como se faz e criar canais de contestação integram uma dimensão indispensável para que mecanismos de controle social da administração possam ser efetivos" (Instituto de Pesquisa Econômica Aplicada [Ipea], 2010, p. 194). O conhecimento dos cidadãos e sobre eles, por sua vez, é relevante para a ação dos governos.

A disponibilidade de informação qualificada, produzida por governos, imprensa e pelos próprios cidadãos e suas organizações, é essencial para o planejamento, a gestão e a avaliação de políticas públicas, para o combate à corrupção e para a efetividade do controle institucional (freios e contrapesos entre poderes e órgãos estatais) e social (dos cidadãos sobre seus governantes) (O'Donnell, 1998, 2004).

Para além disso, na interação entre agentes públicos e cidadãos, são produzidos novas informações e conhecimentos que podem ser úteis para aprimorar processos, políticas e serviços públicos. O engajamento mútuo de cidadãos e governantes na coprodução da informação e do controle (Schommer et al., 2015) permite, ainda, que os cidadãos conheçam os limites que os governos enfrentam para realizar o bem público e, a partir disso, podem redefinir expectativas e se dispor a colaborar mais. Por outro lado, os governantes passam a saber mais sobre as expectativas, pontos de vista e capacidades dos cidadãos, os quais constituem recursos que podem ser mobilizados.

A importância da informação é evidenciada em estudo de Bertolin, Santos, Lima e Braga (2008, p. 63) sobre cooperativismo, quando afirmam que a informação "constitui-se em ingrediente essencial na construção de confiança dos membros em suas transações com a organização". E vão além, afirmando que essa essencialidade abrange a "estruturação das relações do indivíduo com a organização, emergindo como substância vital ao posicionamento deste como ser social, produtivo e gerador de conhecimento".

A expressão em latim Scientia potentia est (conhecimento é poder) leva à consideração, ainda mais objetivada na atualmente denominada "sociedade da informação e do conhecimento", de que, de fato, conhecimento e poder são "irmãos siameses". O filósofo inglês Francis Bacon enfatizava que "saber é poder". Michel Foucault, a seu tempo, destacou e analisou as relações entre o poder e os saberes: "não há relação de poder sem constituição correlata de um campo de saber, nem saber que não suponha e não constitua ao mesmo tempo relações de poder" (Foucault, 2010, p. 30).

São frases e análises que enfatizam a relação estreita entre os saberes e o poder que deles decorre. Na sociedade contemporânea, a cidadania se constitui ao deter o poder de participar e direcionar a vida política da comunidade. Todavia, "cidadãos sem informação sobre os processos decisórios e sobre a implementação de políticas não podem reivindicar, de forma satisfatória, mudanças em seus procedimentos e objetivos" (Ipea, 2010, p. 194). Sem isso, ficam também distantes da possibilidade de contribuir para a solução dos problemas públicos.

Portanto, a existência de informações amplas e fidedignas proporciona o conhecimento e expande as possibilidades de exercício da cidadania. Se usados em processos de discussão, deliberação e ação, aumentam a confiança no sistema político-administrativo e melhoram as condições de participação e engajamento dos cidadãos. 


\section{Confiança}

A confiança é um conceito ambíguo (Greiling, 2014, p. 618) que desafia os estudiosos da administração pública (Kim, 2005, p. 617). Mas, "é certo que confiança nos indivíduos é bastante diferente de confiança em autoridades e instituições políticas" (Putnam, 2000, p. 137).

No que concerne à administração pública, a confiança é vista como um elemento facilitador da boa governança e de ampliação do respeito às instituições, incrementando a atitude cooperativa e compreensiva do cidadão para com as decisões de governo (Greiling, 2014; Kim, 2005).

A preocupação com a falta de confiança no governo e no sistema político e os efeitos prejudiciais que isso tem sobre o próprio governo e sobre a coesão da sociedade é algo presente em diferentes épocas e contextos. Dependendo da presença ou ausência de confiança, haverá cooperação ou polarização. Daí que "a participação pode criar confiança porque identifica e eventualmente harmoniza interesses e torna previsíveis as ações" (Bouckaert \& van de Walle, 2003, pp. 329-335).

Quando se fala em confiança interpessoal em interações comunitárias, o conceito de capital social - aqui referente à natureza e extensão do envolvimento de um indivíduo em várias redes informais e organizações cívicas formais, ou seja, "como um termo conceitual para caracterizar as muitas e variadas maneiras pelas quais os membros de uma comunidade interagem" (Grootaert, Narayan, Nyhan \& Woolcok, 2004, p. 3) -, se apresenta fundamental para se compreender a capacidade que a confiança e as interações comunitárias têm de promover a produção de bens coletivos e o bem comum (Grootaert et al., 2004; Serafim et al., 2012).

O capital social, portanto, se refere à capacidade das pessoas de constituir uma comunidade, de subordinar interesses individuais aos interesses coletivos, de trabalharem juntas visando benefícios mútuos e de compartilhar valores e normas (Franco, 2001). Essa capacidade pressupõe interações sociais que promovem o reconhecimento mútuo, a confiança, a reciprocidade e a solidariedade. E não se trata aqui de virtudes pessoais, mas de virtudes sociais que se estabelecem a partir de laços horizontais de interdependência entre os indivíduos de uma comunidade.

Rennó (2003, p. 36) afirma que "A confiança constrói-se durante um longo período de tempo e, uma vez estabelecida, tende a continuar no tempo, ainda que exija constante exercício".

A confiança estimula a mobilização em torno de assuntos coletivos porque gera expectativas positivas acerca do comportamento dos outros, aí incluído o governo e suas instituições, pois "na essência do conceito de confiança, de acordo com vários autores, está a ideia de reciprocidade", ou seja, "uma pessoa confia em outra porque espera dela um certo tipo de atitude" (Rennó, 2003, p. 73).

A confiança mútua permite a prevalência do interesse comum sobre os interesses individuais, pois os indivíduos, quando não existe confiança, preferem agir isoladamente e não coletivamente, o que confere importância social tanto à cooperação quanto à mobilização política, "justamente por contribuírem indiretamente para 'combater o isolamento e a desconfiança mútua"” (Putnam, 2006, p. 103). Quando o cidadão abandona seus sentimentos de confiança mútua, acaba minando a solidariedade horizontal, mostrando-se menos solidário e participativo na vida da coletividade, unicamente interessado em seu próprio bem-estar e no de sua família (Putnam, 2006, p. 154).

Em estudo que testou a disposição dos indivíduos a se engajarem em ações coletivas, verificou-se que quanto mais um indivíduo entende que sua participação requer muito de seu tempo e esforço, mais a confiança interpessoal representa um diferencial positivo, que tem o efeito de incentivar a formação de grupos de cidadãos com interesses em comum, mas condicionado pelas expectativas individuais de custos e de benefícios da ação coletiva (Freire, 2014).

Há, todavia, riscos. "A confiança é um bem frágil - principalmente no governo" (Behn, 1998, p. 28). Quando os resultados não são atingidos ou quando o cidadão não se sente valorizado, por exemplo, ao invés de ampliar-se a confiança, pode-se gerar desconfiança.

Em pesquisas realizadas por Kang e Ryzin (2019) para investigar como a coprodução pode influenciar a confiança no governo, concluíram que a confiança é condição prévia para se iniciar um processo de coprodução, ainda que tenham encontrado pouco efeito causal da coprodução na confiança. 
A confiança se relaciona com a avaliação do processo de prestação de serviços e a satisfação se correlaciona com a avaliação de resultados. Quando o processo é percebido como inclusivo, participativo e imparcial, a confiança tende a ser promovida (Fledderus, 2015).

Confiança é, pois, ao mesmo tempo fruto de processos relacionais exitosos, construídos ao longo do tempo, como também requisito da participação política e elemento que permite a consolidação da participação e o engajamento do cidadão.

\section{Participação}

A contribuição de Follett à discussão da participação do cidadão na coletividade pode ser aquilatado por uma de suas alcunhas, a de "profeta da participação", pois pressagiava a necessidade de uma administração pública mais democrática pelo engajamento dos cidadãos (Stout \& Love, 2017, p. 372).

A participação, quando restrita às formas definidas pela literatura como participação convencional ou citizen-oriented, refere-se à inclusão dos cidadãos no processo político, elegendo e delegando poder a seus representantes ou envolvido no processo decisório das políticas públicas. Representa, assim, o nível preliminar ao engajamento, que tem a mesma natureza da participação, porém exercido de forma mais profunda e direta, isto é, quando o cidadão está pessoal e diretamente envolvido nas ações e compartilha responsabilidade pelo processo e seus resultados (Stout \& Love, 2017).

Participação e engajamento são aqui tratados, portanto, como níveis diferentes de um mesmo fenômeno no qual os cidadãos compartilham poder com funcionários públicos na "tomada de decisões substantivas" e no desenvolvimento de ações relacionadas à comunidade (Roberts, 2004, p. 320). A participação pressupõe a combinação entre o ambiente político propício e vontade individual.

Em um dos primeiros esforços de sistematização das questões ligadas à participação dos cidadãos na vida política foi feito por Milbrath (1965). O autor, revisando estudos empíricos, distinguiu uma série de formas de participação, que mostravam uma grande variedade de possibilidades da sua ocorrência.

Pesquisas realizadas por Verba e Almond (1963) levaram a uma tipologia das diversas gradações da vontade explícita dos indivíduos de participar, a que chamaram de "cultura cívica". Segundo esses autores, dos três tipos puros de cultura cívica por eles identificados, somente os membros da última categoria, a participativa, se sentiriam motivados a se engajar nas ações relacionadas às suas comunidades e dariam estabilidade às democracias. Na visão de Follett, conforme citada por Stout e Love (2017, p. 71) "A atividade de cocriar é o núcleo da democracia, a essência da cidadania, a condição para ser cidadão do mundo".

Os estudos de Milbrath (1965) e os de Verba e Almond (1963) foram criticados por desconsiderar formas de engajamento não convencional - a exemplo do ativismo político dos movimentos de protesto.

Outra tipologia clássica de participação é a Escada de Participação Cidadã, elaborada por Arnstein (1969), que se estrutura com base na variável "grau de poder" dos cidadãos sobre as decisões e ações de programas governamentais, em diferentes situações empíricas. Pretty (1995), por sua vez, distingue sete tipos de participação, considerando motivações e incentivos para participar e papéis desempenhados pelos cidadãos em iniciativas voltadas ao bem comum. Enquanto White (1996) distingue duas formas principais de planejamento e desenvolvimento da participação que consideram quem participa e o nível de participação.

Axworthy (2004, p. 3), ao discutir o déficit de accountability nas eleições canadenses, afirma que existem relações claras entre participação e accountability, pois, segundo ele, para que os cidadãos se envolvam no processo político, é necessário que tenham informações suficientes para avaliar o desempenho dos eleitos e atribuir responsabilidades. E conclui: "para incentivar o envolvimento do cidadão, devemos consertar o quadro de accountability".

Marques (2009, p. 126), ao estudar as relações entre a comunicação, a mídia e os processos de construção da democracia no município de Belo Horizonte, corrobora a posição do estudo canadense ao afirmar que "as pessoas só se engajam em processos participativos quando motivadas pela certeza de que sua contribuição específica poderá alterar o rumo e a formulação de políticas e normas que as afetam diretamente". 
Contudo, quando a participação não é valorizada e seus resultados não são observados pelo cidadão, corre-se o risco de gerar desengajamento e desconfiança, solapando o processo (Fledderus, 2015; Freire, 2014; Marques, 2009; Putnam, 2006). Há, ainda, o risco do uso da noção de participação para maquiar uma falsa promessa governamental, de integração do cidadão aos processos de debate e de tomada de decisão; e, para qualificar ou validar processos deliberativos formalistas (Marques, 2009).

De qualquer forma, participação e engajamento, que têm na confiança o seu catalisador, são, também, elementos ativos e fundamentais para a accountability.

\section{Accountability}

A accountability pode ser entendida como uma estratégia para atender a um conjunto de expectativas (Heidemann, 2009). No âmbito da administração pública, accountability refere-se a um processo complexo de controle da atividade pública que busca promover a responsabilização permanente dos agentes públicos em razão do uso do poder que lhes é outorgado pela sociedade (Mainwaring \& Welna, 2005, O’Donnell, 1998, 2004; Rocha, 2011).

O processo de accountability requer informações, conhecimento e participação social (Axworthy, 2004; Denhardt \& Denhardt, 2007), sobretudo sob a perspectiva da accountability social (Hernandez \& Cuadros, 2014) ou da coprodução da informação e do controle (Schommer et al., 2015), que enfatiza a relação entre cidadãos e governantes na sua realização.

Hernandez e Cuadros (2014 p. 230, tradução nossa) enfatizam que a accountability não é voluntária, pressupõe quem a demande e aplique. Pode ser considerada como elemento de bem-estar e desenvolvimento socioeconômico: "ser incapaz de demandar accountability é uma condição de pobreza e uma razão para manter-se na pobreza". Os cidadãos são, portanto, corresponsáveis pela accountability, demandando-a dos governantes e colaborando para sua realização na busca de solução para problemas específicos, em cada contexto (Guerzovich, 2020; Thindwa, 2019). O que está em sintonia com o que Follett já assinalava, sugerindo ir além da accountability fundada em hierarquia, em favor de accountability como responsividade, pressupondo responsabilidade compartilhada entre os vários envolvidos em certo problema. Não basta que cada um cumpra bem seu papel, sua parte, é preciso preocupar-se também que as demais partes do sistema tenham com desempenho (Stout \& Love, 2017).

Greiling (2013, p. 40) observa que a accountability é considerada por muitos autores como fator importante para criar e aumentar a confiança do cidadão no governo e nas suas instituições. Kim (2005, p. 630) argumenta que "Um arranjo institucional projetado para garantir a accountability dando poder aos cidadãos, é susceptível de aumentar a aceitação voluntária das decisões e regras da autoridade governamental na medida em que governo e cidadãos ampliam seus valores e interesses compartilhados".

Axworthy (2004, p. 2), observa que "Um sistema de accountability claramente definido é crucial para o nosso sistema de democracia representativa, porque os cidadãos, através do seu voto, legitimam ou dão autoridade aos líderes para agir".

Interessante observar a necessária sinergia entre accountability institucional e social, que se dá a partir da necessidade de um fluxo de informações amplo e aberto, capaz de subsidiar e incentivar a discussão e o debate em torno das questões públicas.

Assim, a produção e divulgação de informações públicas de boa qualidade, que possam ser utilizadas por governantes e cidadãos para analisar e definir cursos de ação, é condição necessária, ainda que não suficiente, para efetivação da accountability pela sociedade (Rocha, 2013). Tal necessidade leva a sociedade a demandar a produção e divulgação de tais informações pelos sistemas institucionais, o que, de certa forma os empodera e legitima. Os cidadãos, por sua vez, podem contribuir para a produção de informações, em complemento e em articulação com as informações produzidas por órgãos de controle institucional do Estado. Estes, idealmente, possuem condições como organização, estrutura, capacidade técnica, pessoal especializado e competência legal que poderão estar a serviço do controle político da sociedade sobre o governo, referenciado como controle social, e do controle político-institucional exercido no interior do aparato estatal, na medida das possibilidades e da efetividade da realização da coprodução (Rocha et al., 2012).

Portanto, é fundamental que os sistemas de controle institucionais funcionem bem para que os processos de accountability social possam se desenvolver a contento. Ambos são interdependentes (Schommer et al., 2015) e compartilham a responsabilidade pelo desempenho do sistema como um todo (Stout \& Love, 2017). 
Na coprodução, a accountability é ainda mais desafiadora do que na administração pública tradicional ou nos modelos de provisão via mercado, pois passa por critérios mais subjetivos: os mesmos atores desempenham mais de um papel - os que controlam são os que se envolvem nas decisões e na execução (Denhardt \& Denhardt, 2007; Rocha, 2011). Além disso, não se resumo ao ciclo eleitoral ou ao momento das eleições, incluindo o cotidiano do exercício dos mandatos e os ciclos das políticas públicas.

Em artigo que discutiu a accountability nos arranjos de governança quando um serviço público - a conciliação judicial - é realizado por meio da coprodução, Tuurnas, Stenvall e Rannisto (2016, p. 131) concluem que "a coprodução entre voluntários e profissionais aumenta os laços de responsabilização. [...] a coprodução como arranjo de governança modifica a cultura de trabalho dos profissionais do serviço público". No caso estudado a accountability profissional, o controle social e a avaliação por pares contribuem para "evitar que se estabeleçam políticas baseadas nos interesses mútuos de um grupo" (Tuurnas et al., 2016, p. 141). Os mesmos autores enfatizam "que os arranjos de governança mudam a lógica de prestação de serviços profissionais, com implicações especialmente para as relações de responsabilização" (Tuurnas et al., 2016, p. 145).

No mesmo sentido, Schommer et al. (2015), ao analisarem experiências de colaboração entre organizações da sociedade civil e órgãos de controle institucional em municípios brasileiros, concluíram que tal articulação contribui para ativar o sistema de accountability local e nacional, propiciando melhores resultados em informação, justificação, recompensas e punições aos agentes públicos.

Assim, a accountability compõe e de certa forma sintetiza a perspectiva sistêmica do processo integrativo dos elementos estruturantes da coprodução.

\section{Coprodução - Visão Integrativa}

Diversos autores definem tipologias de coprodução, considerando os papéis, os graus de compartilhamento de poder e as etapas do processo de coprodução em que ocorre o engajamento entre os envolvidos na coprodução (Bovaird, 2007; Brandsen \& Hoeningh, 2016; Nabatchi, Sancino \& Sicilia, 2017; Pestoff, 2018b; Salm \& Menegasso, 2010).

Salm e Menegasso (2010, pp. 13-14), por exemplo, consideram diferentes formas e graus de poder na participação para distinguir cinco modelos de coprodução de serviços públicos: Coprodução Nominal, na qual se busca a eficiência dos serviços públicos e não há participação efetiva e de poder do cidadão sobre o Estado; Coprodução Simbólica, de caráter manipulativo, visando demonstrar a presença e a eficácia do Estado; Coprodução Funcional, a qual se dá por meio da solicitação dos serviços, de assistência ao Estado ou por um ajuste mútuo com o Estado, e visa a implementação eficiente das políticas públicas; Coprodução Representativa com Sustentabilidade, que resulta da interação do cidadão com o aparato administrativo e da delegação de poder pelo Estado. "Neste modelo, o empowerment e a accountability são essenciais, já que o modelo requer o engajamento cívico do cidadão e da comunidade"; e Coprodução para a Mobilização Comunitária, onde os serviços públicos são coproduzidos como uma estratégia para a permanente mobilização da comunidade e de superação da organização burocrática. "O modelo se propõe a transformar a comunidade e o aparato público do Estado", baseado nos princípios éticos e democráticos.

Pestoff (2018b), por sua vez, discute os papéis de servidores públicos, cidadãos e provedores privados em quatro diferentes modelos de administração pública. No modelo tradicional, os cidadãos são apenas beneficiários, sem voz, sem escolha, sem controle e sem participação efetiva. No modelo comunitário, os cidadãos produzem por si próprios os bens e serviços públicos de que precisam, geralmente pela ausência do Estado e por falta de alternativas para os cidadãos, ou seja, não há autêntica coprodução. No modelo da nova gestão pública, os provedores privados ganham protagonismo e o papel do usuário é de escolha, mais como consumidor do que como cidadão ativo, com voz e ação sobre os rumos do bem ou serviço. Na nova governança pública, na qual ocorre a coprodução, os cidadãos participam e tem voz e influência política, e tem a opção de desengajar-se, caso não queiram participar.

Outras tipologias existem, todavia o que é importante neste ponto é mostrar que a coprodução é, em última análise, um processo de interações entre indivíduos e grupos, moldadas por motivações e atitudes. Diferente das interações ocorridas nas organizações formais, as motivações na coprodução são diversas - por vínculo funcional, no caso dos agentes públicos; e por interesse próprio, no caso do cidadão, ainda que tal interesse diga respeito apenas ao próprio indivíduo ou à coletividade -, pois o fato é que tais interações ocorrem em termos relacionais e não contratuais. 
Assim, ao se entender a coprodução como um processo integrativo nos moldes follettianos, o qual permite "transformar nosso entendimento do conflito como problema social para enxergar a diferença como oportunidade para um processo auto-organizador, construtivo, unificador, harmonizador e sintetizador que gera poder compartilhado e progresso" (Stout \& Love, 2017, p. 356), os processos de coprodução abandonam a perspectiva de uma administração formal, hierárquica e impositiva, por uma "função social fluida de harmonização de diferenças", ou seja, "uma governança colaborativa" (Stout \& Love, 2017, p. 357).

Portanto, se na coprodução não há vínculos laborais formais que obriguem o cidadão a coproduzir, sua adesão ao processo só se dará à medida que acredite no próprio processo, nos benefícios que dele advirão, e se sinta parte dele. $\mathrm{O}$ gestor público, por sua vez, é demandado e induzido a coordenar um processo integrativo de elementos, funções e interesses convergentes, valorizando a contribuição de todos os envolvidos e comprometido com os resultados. Essas condições serão atingidas quando, compreendida a natureza do processo, os elementos que lhes dão sustentação social estejam presentes. E aí ter-se-á a possibilidade da coesão social necessária à sustentação da coprodução, a qual subsistirá à medida que seus elementos subsistam.

Entretanto, a coprodução, mesmo quando ocorre de maneira efetiva, compartilhando poder e alcançando resultados, apresenta riscos. Bovaird e Loefler (2013, p. 9) alertam que muitas iniciativas focam as "necessidades" em vez de "necessidades e capacidades", o que pode significar uma variação muito grande em termos de resultados de um lugar para outro e comprometer a confiança que o cidadão, e o próprio governo, depositam no processo. Também é possível que se constitua como um tipo de relação que pode acabar por destruir transparência, confiança, participação e accountability em decorrência da desconfiança do cidadão na capacidade do Estado de cumprir com as suas promessas e obrigações em relação à própria coprodução (Steen, Brandsen \& Verschuere, 2018). Além disso, embora se espere que a coprodução, sob certas condições, gere sinergia (Ostrom, 1996), a depender de como o processo é conduzido, a coprodução pode diminui-la (Kang \& Ryzin, 2019), destruindo valor público ao invés de adicioná-lo (Bovaird \& Loeffler, 2013). Ademais, a coprodução será impraticável se não houver efetiva redistribuição do poder, o poder com em lugar do poder sobre de que trata Follett (Stout \& Love, 2017) para que os cidadãos se sintam incluídos e influenciem as políticas públicas. Nesse sentido, a redistribuição do poder deve ser entendida de forma categórica, pois só assim os cidadãos excluídos do processo político se sentirão estimulados a participar (Arnstein, 1969).

Em resumo, a coprodução como elemento central e objetivo final de um processo complexo, multifacetado e deliberado que pode servir como resposta ao desequilíbrio e ao conflito "improdutivo" (Stout \& Love, 2017); à escassez de recursos e de legitimidade governamentais (Brandsen \& Honingh, 2016), embora naturalmente envolva riscos (Bovaird \& Loeffler, 2014; Brandsen et al., 2018; Kang \& Ryzin, 2019), depende e influencia os elementos que lhes dão sustentação. Demanda e implementa a transparência em relação aos processos produtivos e seus resultados. Qualifica as informações e o conhecimento, uma vez que a existência de informações amplas e fidedignas proporciona o conhecimento e expande as possibilidades de exercício da cidadania, aumentando a confiança no sistema político-administrativo e melhorando as condições de participação e engajamento dos cidadãos. Aumenta a confiança, a qual se relaciona com a avaliação dos processos de prestação de serviços e a obtenção de resultados. Vincula a participação e o engajamento do cidadão e da comunidade aos esforços de produção dos serviços públicos, e promove a accountability, a qual, por sua vez, amplia, reforça e retroalimenta todo o processo, fortalecendo-o e desenvolvendo-o.

Entretanto, cabe destacar que a discussão aqui proposta está recém-iniciada. Não se pretende uma conclusão definitiva sobre os elementos e suas relações, mas indicar caminhos para se avançar na proposição do modelo teórico de análise integrativa da coprodução. Isso exige um exame detalhado e em diferentes ordens e níveis de análise em pesquisas empíricas progressivas, por elemento e no seu conjunto, de forma a responder questões básicas, como por exemplo: qual a intensidades dessas relações? Em que medida os elementos são pré-condições para a coprodução? Existe hierarquia entre eles? Eles são necessário e/ou se constituem em uma resposta efetiva de viabilização da coprodução em contextos de conflito? E em contextos de harmonia (não conflito)? E outras questões definidoras de pesquisa futura que permitirão chegar-se à estruturação do modelo propriamente dito. 


\section{CONSIDERAÇõES FINAIS}

No atual contexto de crise política e econômica, a complexidade dos desafios e as necessidades coletivas são superiores à capacidade de resposta dos governos. A exacerbação de conflitos e tensões sociais exige contrapontos que conduzam a um novo equilíbrio, por meio da colaboração e da harmonização. As crescentes demandas por mais e melhores serviços públicos dificultam a sua prestação face à elevação dos custos. A solução passa a ser a adoção de estratégias diferenciadas e criativas de enfrentamento do problema e entrega desses serviços, mobilizando, articulando e coordenando diversos recursos existentes na sociedade.

Além dos aspectos financeiros, a aproximação entre governantes e cidadãos pode contribuir para recuperar a legitimidade política dos governos, dado o momento de ceticismo e perplexidade gerado por investigações de corrupção, mau uso dos recursos públicos e novos desafios globais. Em resposta a isso, em lugar de respostas autoritárias e simplificadoras, a possibilidade de respostas participativas e criativas, que fortaleçam a cidadania e a democracia.

De acordo com o que já observava Follett (1998), o progresso depende não apenas de condições econômicas, físicas ou biológicas, também de capacidade de cooperação genuína, ou da ampliação contínua de nossa capacidade de associação e de realização da democracia cocriativa em todas as esferas da sociedade (Stout \& Love, 2017).

É nesse cenário que a coprodução surge como caminho para equilibrar expectativas, justificar a falta de recursos, mobilizar outros tipos e fontes de recursos, promover accountability e engajar servidores e cidadãos na provisão de serviços e no enfrentamento dos desafios públicos.

Entretanto, a coprodução não se dá ao acaso. É um processo complexo que, abordado a partir de uma visão integrativa, pode ser estudado, compreendido e estruturado de forma mais ampla. A coprodução, como uma estratégia de ação governamental que busca produzir em conjunto com os cidadãos os bens e serviços públicos que estes demandam, pressupõe - e necessita de proatividade do poder público, traduzida no necessário compartilhamento do poder e do fazer com o cidadão, e de uma postura responsiva do cidadão, cuja atitude participativa ultrapassa ações corriqueiras e pontuais, expressando uma consciência de pertencer e fazer parte de um processo produtivo, democrático em sua essência, mas em contínua transformação. Aos gestores públicos, que são também cidadãos "com responsabilidades especiais" (Stout \& Love, 2017, p. 374), cabe a especial tarefa de coordenar um processo integrativo de elementos, funções e interesses convergentes. Como tal, a adesão de servidores públicos e cidadãos à coprodução de bens e serviços públicos só se dará na medida em que acreditem no processo, e só permanecerá enquanto se sentirem parte dele e nele perceberem os elementos que reforçam e revigoram a coesão social necessária à sua sustentação.

Há que se ter o cuidado, no entanto, de perceber que as limitações fiscais (ou quaisquer outros motivos pertinentes) ao mesmo tempo que podem ser um incentivo à coprodução e à valorização da capacidade dos cidadãos, também podem representar uma possível redução (ou retirada) do Estado da prestação de serviços e garantia de direitos.

Por fim, não custa reafirmar: este é um trabalho inicial, cuja proposta foi trazer à discussão a proposição de que transparência, informação, confiança, participação e accountability são elementos estruturantes da coprodução e que, a partir de uma visão fundamentada nos pressupostos ontológicos e elementos do processo integrativo que consagram a perspectiva sistêmica da associação e atuação dos seres humanos em grupo, conforme defendido por Mary Parker Follett, é possível vislumbrar caminhos para o desenvolvimento de um modelo de análise com base na coesão social que se assenta na perspectiva sistêmica da associação e atuação de indivíduos em grupo que sustentam o seu envolvimento em motivações e atitudes. Todavia, avançar na proposição do modelo propriamente dito é tarefa em curso que demanda, para além da discussão dos aspectos teóricos, pesquisas empíricas que consolidem e detalhem as inter-relações aqui apresentadas.

\section{AGRADECIMENTOS}

Os autores agradecem à Fundação de Amparo à Pesquisa e Inovação do Estado de Santa Catarina, Fapesc, pelo apoio financeiro por meio do Programa de Apoio à Pesquisa, PAP-Udesc. 


\section{REFERÊNCIAS}

Alford, J. (2009). Engaging public sector clients: from service-delivery to co-production. Basingstoke, UK: Palgrave Macmillan.

Angélico, F. (2015). Lei de acesso à informação: reforço ao controle democrático. São Paulo, SP: Estúdio editores.

Arnstein, S. R. (1969). A ladder of citizen participation. Journal of the American Institute of Planners, 35(4), 216-224.

Axworthy, T. S. (2004). Addressing the accountability deficit: why Paul Martin's minority government must pay more attention to the three A's (Working Paper, 2004-11). Montreal, Canada: Institute for Research on Public Policy.

Behn, R. D. (1998). O novo paradigma da gestão pública e a busca da accountability democrática. Revista do Serviço Público, 49(4), 5-45. Recuperado de https://revista.enap.gov.br/index.php/RSP/ article/view/399/524

Bertolin, R. V., Santos, A. C., Lima, J. B., \& Braga, M. J. (2008). Assimetria de informação e confiança em interações cooperativas. Revista de Administração Contemporânea, 12(1), 59-81. Recuperado de https:// rac.anpad.org.br/index.php/rac/article/view/586/583

Bouckaert, G., \& Walle, S. (2003). Comparing citizen trust and user satisfaction as indicators of good governance. International Review of Administrative Sciences, 69(3), 329-343. Recuperado de https://journals.sagepub.com/ doi/10.1177/0020852303693003\#articleCitationDownloadContainer

Bovaird, T. (2007). Beyond engagement \& participation: user \& community co-production of public services. Public Administration Review, 67(5), 846-860. Recuperado de https://onlinelibrary.wiley. com/doi/abs/10.1111/j.1540-6210.2007.00773.x

Bovaird, T., \& Loefller, E. (2013, junho). We're all in this together: harnessing user and community co-production of public outcomes. Birmingham, UK: University of Birmingham. Recuperado de: https:// www.birmingham.ac.uk/Documents/college-social-sciences/government -society/inlogov/publications/2013/chapter-4-bovaird-loeffler.pdf

Bovaird, T., Flemig, S., Loeffler, E., \& Osborne, S. P. (2017). Debate: co-production of public services and outcomes. Public Money \& Management, 37(5), 363-364. Recuperado de: https://www. tandfonline.com/doi/abs/10.1080/09540962.2017.1294866

Brandsen, T., \& Honingh, M. (2016). Distinguishing different types of coproduction: a conceptual analysis based on the classical definitions. Public Administration Review, 76(3), 427-435. Recuperado de https:// onlinelibrary.wiley.com/doi/abs/10.1111/puar.12465

Brandsen, T., Steen, T, \& Verschuere, B. (2018). Co-production and co-creation: engaging citizens in public services. Abingdon, UK: Taylor \& Francis, 2018

Brudney, J., \& England, R. E. (1983). Toward a definition of the coproduction concept. Public Administration Review, 43(1), 59-65. Recuperado de https://www.jstor.org/stable/975300?seq=1

Denhardt, J. V., \& Denhardt, R. B. (2007). The new public service: serving, not steering (Exp. Edition). New York, NY: M. E. Sharpe.

Denhardt, R. B. (2012). Teorias da administração pública. São Paulo, SP: Cengage Learning.
Doin, G. A., Dahmer, J., Schommer, P. C., \& Spaniol, E. L. (2012). Mobilização social e coprodução do controle: o que sinalizam os processos de construção da lei da ficha limpa e da rede observatório social do brasil de controle social. Pensamento \& Realidade, 27(2), 56-79. Recuperado de https://revistas.pucsp.br/index.php/ pensamentorealidade/article/viewFile/12648/9211

Emerson, K., Nabatchi, T., \& Balogh, S. (2012). An integrative framework for collaborative governance. Journal of Public Administration Research and Theory, 22(1), 1-29. Recuperado de https://academic. oup.com/jpart/article/22/1/1/944908

Fledderus, J. (2015). Building trust public services co-prodution. International Journal of Public Sector Management, 28(7), 650665. Recuperado de https://www.emerald.com/insight/content/ doi/10.1108/IJPSM-06-2015-0118/full/html

Follet, M. P. (1998 [1918]). The new state: group organization the solution of popular government. University Park, Pennsylvania: Pennsylvania State University Press.

Follet, M. P. (2003 [1942]). The giving of orders. In H. C. Metcalf, \& L. Urwick (Org.), Dynamic administration: the collected papers of Mary Parker Follett (pp. 50-70). New York, NY: Routledge.

Foucault, M. (2010). A ordem do discurso. São Paulo, SP: Editora Loyola.

Franco, A. (2001). Capital social: leituras de Tocqueville, Jacobs, Putnam, Fukuyama, Maturana, Castells e Levy. Brasília, DF: Instituto de Política/Millennium.

Freire, A. (2014). Engajamento cívico e capital social: um modelo interativo para o efeito da confiança interpessoal. Opinião Pública, 20(2), 273-290. Recuperado de https://www.scielo.br/scielo. php?script=sci_arttext $\&$ pid=S0104-62762014000200273

Greiling, D. (2013). Public accountability and citizen trust: it takes two to tango. ZögU Beiheft, 42, 39-66.

Greiling, D. (2014). Accountability and trust. In M. Bovens, R. E. Goodin, \& T, Schillemans (Org.), The Oxford handbook of public accountability (pp. 617-631). Oxford, UK: Oxford University Press.

Grootaert, G., Narayan, D., Nyhan J. V., \& Woolcock, M. (2004). Measuring social capital: an integrated questionnaire (World Bank Working Paper, 18). Washington, DC: World Bank. Recuperado de https://openknowledge.worldbank.org/handle/10986/15033

Guerzovich, F. (2020). What do we need to close the gap between what social accountability looks like in 2020 and how we talk about it? (Part 2B). Washington, DC: Global Partnership for Social Accountability. Recuperado de https://gpsaknowledge.org/what-do-we-need-toclose-the-gap-between-what-social-accountability-looks-like-in2020-and-how-we-talk-about-it-part-2b/

Guerzovich, F., \& Schommer, P. C. (2016). Four ways in which social accountability and open government interventions bridge the state and society (ISTR Working Paper Series). In Proceedings of the 12 ISTR Conference, Stockholm, Sweden.

Heidemann, F. G. (2009). Ética de responsabilidade: sensibilidade e correspondência a promessas e expectativas contratadas. In F. G. Heidemann, \& J. F. Salm (Org.), Políticas públicas e desenvolvimento: 
bases epistemológicas e modelos de análise (pp. 301-309). Brasília, DF: Universidade de Brasília.

Hernandez, A., \& Cuadros, D. (2014). Iniciativas de transparencia y accountability en América Latina: naturaleza, tipología e incidencia en la democracia y el desarrollo. In D. M. Pinheiro, D. Melo, \& J. Costa (Org.), Democracia: desafios, oportunidades e tendências (pp. 221265). Florianópolis: Imaginar o Brasil. Recuperado de https://www. researchgate.net/publication/332438150_DEMOCRACIA_desafios_ oportunidades_e_tendencias

Instituto de Pesquisa Econômica Aplicada. (2010). Estado, instituições e democracia: democracia (Livro 9, vol. 2, Série Eixos Estratégicos do Desenvolvimento Brasileiro). Brasília, DF: Autor. Recuperado de http://www.ipea.gov.br/portal/index. php?option=com_content $\&$ view=article \&id=6491

Kang, S., \& Ryzin, G. V. (2019). Coproduction and trust in government: evidence from survey experiments. Public Management Review, 21(1), 1646-1664. Recuperado de https://www.tandfonline.com/ doi/abs/10.1080/14719037.2019.1619812

Kim, S. E. (2005). The role of trust in the modern administrative state: an integrative model. Administration \& Society, 37(5), 611-635. Recuperado de https://journals.sagepub.com/doi/10.1177/0095399705278596

Mainwaring, S., \& Welna, C. (2005). Democratic accountability in Latin America (Oxford Studies in Democratization Series). Oxford, UK: Oxford University Press.

Marques, A. C. S. (2009). Comunicação, mídia e processos de democracia local: estratégias de aproximação entre governo e cidadãos. Opinião Pública, 15(1), 107-132. Recuperado de https://www.scielo.br/scielo. php?script=sci_arttext\&pid=S0104-62762009000100005

Marschall, M. J. (2004). Citizen participation and the neighborhood context: A new look at the co-production of local public goods. Political Research Quarterly, 57(2), 231-244. Recuperado de https://journals. sagepub.com/doi/10.1177/106591290405700205

Milbrath, L. W. (1965). Political participation: how and why do people get involved in politics? Chicago, Illinois: Rand McNally.

Nabatchi, T., Sancino, A., \& Sicilia, M. (2017). Varieties of participation in public services: the who, when, and what of coproduction. Public Administration Review, 77(5), 766-776. Recuperado de https:// onlinelibrary.wiley.com/doi/abs/10.1111/puar.12765

O'Donnell, G. (1998). Accountability horizontal e novas poliarquias. Revista Lua Nova, 44, 27-54. Recuperado de https://www.scielo.br/ $\mathrm{pdf} / \mathrm{ln} / \mathrm{n} 44 / \mathrm{a} 03 \mathrm{n} 44 . \mathrm{pdf}$

O’Donnell, G. (2004). Accountability horizontal: la institucionalización legal de la desconfianza política. Revista Española de Ciencia Política, 11, 11-31. Recuperado de https://recyt.fecyt.es/index.php/recp/ article/view/37355

Ostrom, E. (1996). Crossing the great divide: co-production, synergy and development. World Development, 24(6), 1073-1087. Recuperado de https://www.sciencedirect.com/science/article/abs/ pii/0305750X9600023X

Paré, G., Trudel, M. C., Jaana, M., \& Kitsiou, S. (2015). Synthesizing information systems knowledge: a typology of literature reviews. Information \& Management, 52(2), 183-199. Recuperado de https:// www.sciencedirect.com/science/article/abs/pii/S0378720614001116
Park, H., \& Blenkinsopp, J. (2011). The roles of transparency and trust between corruption and citizen satisfaction. International Review of Administrative Sciences, 77(2), 254-274. Recuperado de https:// journals.sagepub.com/doi/10.1177/0020852311399230

Pestoff, V. (2009). Towards a paradigm of democratic participation: citizen participation and co-production of personal social services in Sweden. Annals of Public and Cooperative Economics, 80(2), 197-224.

Pestoff, V. (2018a). Small groups, collective action and the sustainability of co-production. In V. Pestoff (Org.), Co-production and public service management: citizenship, governance and public services management. New York, NY: Routledge.

Pestoff, V. (2018b). Co-production at the crossroads of public administration regimes. In T. Brandsen, T. Steen, \& B. Verschuere (Orgs.), Co-production and co-creation: engaging citizens in public services (pp. 27-36). Abingdon, UK: Taylor \& Francis.

Pretty, J. N. (1995). Participatory learning for sustainable agriculture. World Development, 23(8), 1247-1263.

Putnam, R. (2000). Bowling alone. New York, NY: Simon \& Shuster Paperbacks.

Putnam, R. (2006). Comunidade e democracia: a experiência da Itália moderna (5a ed.). Rio de Janeiro, RJ: Fundação Getulio Vargas.

Rennó, L. R. (2003). Estruturas de oportunidade política e engajamento em organizações da sociedade civil: um estudo comparado sobre a América Latina. Revista de Sociologia e Política, 11(21), 71-82. Recuperado de https://www.scielo.br/scielo.php? script=sci_arttext\&pid=S0104-44782003000200006\&lng=en\&nrm $=$ iso\&tlng=pt

Roberts, N. (2004). Public deliberation in an age of direct citizen participation. The American Review of Public Administration, 34(4), 315-353. Recuperado de https://journals.sagepub.com/ doi/10.1177/0275074004269288

Robredo, J. (2011). Filosofia e informação? Reflexões. RICI: R. Iberoamer. Ci. Inf., 4(2), 1-39. Recuperado de https://periodicos.unb.br/ index.php/RICl/article/view/1671

Rocha, A. C. (2011). Accountability na administração pública: modelos teóricos e abordagens. Contabilidade, Gestão e Governança, 14(2), 82-97. Recuperado de https://www.revistacgg.org/contabil/article/ view/314/pdf_162

Rocha, A. C. (2013). A realização da accountability em pareceres prévios do Tribunal de Contas de Santa Catarina. Revista de Administração Pública, 47(4), 901-25. Recuperado de https://www.scielo.br/scielo. php?script=sci_arttext\&pid=S0034-76122013000400005

Rocha, A. C., Schommer, P. C., Spaniol, E. L., \& Souza, A. D. (2012). Coprodução do controle como bem público essencial à accountability. In Anais 36을 Encontro da ANPAD, Rio de Janeiro, RJ.

Rocha, A. C., Schommer, P. C., Debetir, E., \& Pinheiro, D. M. (2019). Transparência como elemento da coprodução na pavimentação de vias públicas. Cadernos Gestão Pública e Cidadania, 24(78), 1-22. Recuperado de http://bibliotecadigital.fgv.br/ojs/index.php/cgpc/ article/view/74929

Rother, E. T. (2007). Revisão sistemática x revisão narrativa. Acta Paulista de Enfermagem, 20(2), 5-6. Recuperado de https://www.scielo. $\mathrm{br} /$ scielo.php?script=sci_arttext\&pid=S0103-21002007000200001 
Salm, J. F., \& Menegasso, M. E. (2010). Proposta de modelos para a coprodução a partir das tipologias de participação. In Anais do 34은 Encontro da ANPAD, Rio de Janeiro, RJ.

Scharff, M. (2011). Building trust and promoting accountability: Jesse Robredo and Naga City, Philippines, 1988-1998. Innovations for Successful Societies. Princeton, NJ: Princeton University. Recuperado de https://successfulsocieties.princeton.edu/sites/successfulsocieties/ files/Policy_Note_ID158.pdf

Schommer, P. C., Rocha, A. C., Spaniol, E. L., Dahmer, J., \& Sousa, A. D. (2015). Accountability and co-production of information and control. Revista de Administração Pública, 49(6), 1375-1400. Recuperado de http://bibliotecadigital.fgv.br/ojs/index.php/rap/ article/view/56590/pdf_23

Serafim, M. C., Ronconi, L. F. A., Debetir, E., Jara, E. J., Reis, P. C. G., \& Maurício, B. M. (2012). Capital social, confiança e solidariedade na comunidade da Costa da Lagoa. In Anais do 36을 Encontro da ANPAD, Rio de Janeiro: RJ.

Steen, T., Brandsen, T., \& Verschuere, B. (2018). The dark side of co-creation and co-production: seven evils. In T. Brandsen, T. Steen, \& B. Verschuere (Orgs.), Co-production and co-creation: engaging citizens in public services ( $p p$ 284-293). Abingdon, UK: Taylor \& Francis.
Stout, M., \& Love, J. (2017). Processo integrativo: o pensamento de Mary Parquer Follett, da ontologia à administração. Curitiba, PR: InterSaberes.

Thindwa, J. (2019). Reflection on the 2019 GPSA Global Partners Forum. Washington, DC: Global Partnership for Social Accountability. Recuperado de https://www.thegpsa.org/blogs/ reflection-2019-gpsa-global-partners-forum-jeff-thindwa

Tuurnas, S., Stenvall, J., \& Rannisto, P. H. (2016). The impact of co-production on frontline accountability: the case of the conciliation service. International Review of Administrative Sciences, 82(1), 131-149. Recuperado de https://journals.sagepub.com/doi/ full/10.1177/0020852314566010

Verba, S., \& Almond, G. (1963). The civic culture: political attitudes and democracy in five nations. Princeton, NJ: Princeton University Press.

Verschuere, B., Brandsen, T., \& Pestoff, V. (2012). Co-production: the state of the art in research and the future agenda. Voluntas: International Journal of Voluntary and Nonprofit Organizations, 23(4), 1083-1101. Recuperado de https://link.springer.com/article/10.1007/ s11266-012-9307-8

White, S. C. (1996). Depoliticising development: the uses and abuses of participation. Development in Practice, 6(1), 6-15. Recuperado de https:// www.tandfonline.com/doi/abs/10.1080/0961452961000157564

Arlindo Carvalho Rocha

ORCID: https://orcid.org/0000-0003-1193-2244

Doutor em administração; Professor e pesquisador do grupo de pesquisa Politeia do Centro de Ciências da Administração e Socioeconômicas da Universidade do Estado de Santa Catarina (UDESC ESAG). E-mail: arlindo.rocha@udesc.br

Paula Chies Schommer

ORCID: https://orcid.org/0000-0001-9919-0809

Doutora em administração de empresas; Professora de administração pública e pesquisadora do grupo de pesquisa Politeia - Coprodução do bem público: accountability e gestão do Centro de Ciências da Administração e Socioeconômicas da Universidade do Estado de Santa Catarina (UDESC ESAG); Professora colaboradora do Programa de Desenvolvimento e Gestão Social da Universidade Federal da Bahia (UFBA). E-mail: paulacs3@gmail.com

Emiliana Debetir ORCID: https://orcid.org/0000-0002-0998-1226

Doutora em engenharia civil; Mestre em administração; Professora de administração pública e pesquisadora do grupo de pesquisa Politeia Coprodução do bem público: accountability e gestão do Centro de Ciências da Administração e Socioeconômicas da Universidade do Estado de Santa Catarina (UDESC ESAG). E-mail: emilianadebetir@gmail.com

Daniel Moraes Pinheiro

ORCID: https://orcid.org/0000-0002-7731-8178

Doutor em Administração pela Universidade Federal de Santa Catarina (UFSC); Professor do Programa de Pós-graduação em Administração e do Departamento de Administração Pública da Universidade do Estado de Santa Catarina (UDESC); Pesquisador do Núcleo de Inovações Sociais na Esfera Pública (NISP). E-mail: daniel.pinheiro@udesc.br 